\title{
Structural Evolution of P92-Type Martensitic Steel during Creep at $650^{\circ} \mathrm{C}$
}

\author{
A. Fedoseeva*, I. Nikitin, N. Dudova And R. Kaibyshev \\ Belgorod National Research University, Pobeda 85, 308015 Belgorod, Russia
}

\begin{abstract}
Microstructure and a dispersion of secondary phase particles were examined in P92-type steel after creep test at temperature of $650{ }^{\circ} \mathrm{C}$ and an applied stress of $80 \mathrm{MPa}$ in grip, gauge and necked portions of specimens. Normalization at $1050^{\circ} \mathrm{C}$ and tempering at $780^{\circ} \mathrm{C}$ for $3 \mathrm{~h}$ led to the formation mixed structure consisting of tempered martensite lath structure and subgrains. Long-term aging for $9273 \mathrm{~h}$ led to the formation of fully subgrain structure but the average subgrain sizes after tempering and after long-term aging were nearly the same. The structural changes in the gauge and necked sections were characterized by transformation of the tempered martensite lath structure into relatively coarse subgrain one accompanied by the coarsening of $\mathrm{M}_{23} \mathrm{C}_{6}$ carbides and precipitation of the Laves phase. No significant effect of creep strain on particle coarsening was found.
\end{abstract}

DOI: 10.12693/APhysPolA.134.644

PACS/topics: 9\% Cr martensitic steel, creep, aging, subgrains, polygonization

\section{Introduction}

Grade P92 (9Cr-2W-VNbB-type) steel is widely used as material for boilers and tubes of fossil power plants with service temperature of $600^{\circ} \mathrm{C}[1,2]$. The high creep resistance of these high-chromium steels is associated with the formation of a tempered martensite lath structure (TMLS) during tempering at $720-780^{\circ} \mathrm{C}$. TMLS consists of prior austenite grains (PAG), packets, blocks, laths and contains a high density of dislocations and a dispersion of secondary phase particles. $\mathrm{M}_{23} \mathrm{C}_{6}$-type carbides and MX carbonitrides precipitate along boundaries and within ferritic matrix, respectively, during tempering, and the Laves phase particles, $\mathrm{Fe}_{2}$ (W,Mo), precipitate at boundaries under creep conditions [1-7]. An increase in tempering temperature leads to an increase in the width of martensitic laths and coarsening of $\mathrm{M}_{23} \mathrm{C}_{6}$ particles and MX carbonitrides, which can be more stable during long-term aging and creep [8]. Thermal recovery upon long-term aging and creep could be accompanied by the transformation of nanoscale MX carbonitrides into the coarse Z-phase particles and coarsening of boundary $\mathrm{M}_{23} \mathrm{C}_{6}$ carbides and Laves phase $[8,9]$. The coarsening of the boundary particles initiates the transformation of lath boundaries into subboundaries; the internal longrange strain fields originated from lath boundaries relive $[8,9]$. The aim of the present work is to report structural characteristics of P92-type steel tempered at $780^{\circ} \mathrm{C}$ after long-term aging and creep at $650^{\circ} \mathrm{C}$.

\section{Material and methods}

P92-type steel with the chemical composition (in wt\%) of $\mathrm{Fe}_{b a l}-0.1 \mathrm{C}-0.17 \mathrm{Si}-0.54 \mathrm{Mn}-8.75 \mathrm{Cr}-0.51 \mathrm{Mo}-$ $1.6 \mathrm{~W}-0.23 \mathrm{~V}-0.07 \mathrm{Nb}-0.04 \mathrm{~N}-0.003 \mathrm{~B}$ was normalized

\footnotetext{
*corresponding author; e-mail: fedoseeva@bsu.edu.ru
}

at $1050{ }^{\circ} \mathrm{C}$ for $0.5 \mathrm{~h}$ followed by tempering at $780^{\circ} \mathrm{C}$ for $3 \mathrm{~h}$. Cylindrical specimen with a gauge length of $100 \mathrm{~mm}$ and a $10 \mathrm{~mm}$ diameter was crept until rupture at $6500^{\circ} \mathrm{C}$ and an applied stress of $80 \mathrm{MPa}$ using an ATS2330 lever arm machine. Microstructural characterization was performed in the grip, gauge and necked portions of ruptured specimen using a JEM-2100 transmission electron microscope (TEM) equipped with an INCA energy dispersive X-ray spectroscope. The lath/subgrain sizes were evaluated on TEM micrographs by the linear intercept method including all clearly visible (sub)boundaries. The dislocation density was estimated by counting the individual dislocations in the grain/subgrain interiors per unit area on at least six arbitrarily selected typical TEM images for each data point. The mean size of the secondary phase particles was evaluated on TEM micrographs. The precipitates were identified by chemical composition and diffraction pattern analysis. Other details of structural characterization and specimen preparation were reported previously $[3-5,8,10-13]$. Equilibrium fractions of phases were calculated by the Thermo-Calc software using the TCFE7 database.

\section{Results}

\subsection{Microstructure after normalizing and tempering}

Typical microstructure is presented in Fig. 1, and structural parameters are summarized in Table I.

Structural parameters of steel after TABLE I normalization and tempering at $780^{\circ} \mathrm{C}$.

\begin{tabular}{c|c|c|c|c|r}
\hline \hline $\begin{array}{c}D_{\mathrm{PAG}} \\
{[\mu \mathrm{m}]}\end{array}$ & $\begin{array}{c}D_{\text {subgrains }} \\
{[\mu \mathrm{m}]}\end{array}$ & $\begin{array}{c}\rho_{\perp} \times 10^{14} \\
{\left[\mathrm{~m}^{-2}\right]}\end{array}$ & $\begin{array}{c}d_{\mathrm{M} 23 \mathrm{C} 6} \\
{[\mathrm{~nm}]}\end{array}$ & $\begin{array}{c}d_{\mathrm{VX}} \\
{[\mathrm{nm}]}\end{array}$ & $\begin{array}{c}d_{\mathrm{NbX}} \\
{[\mathrm{nm}]}\end{array}$ \\
\hline $20 \pm 2$ & $0.46 \pm 0.15$ & $2.5 \pm 1$ & $106 \pm 3$ & $56 \pm 5$ & $55 \pm 5$
\end{tabular}




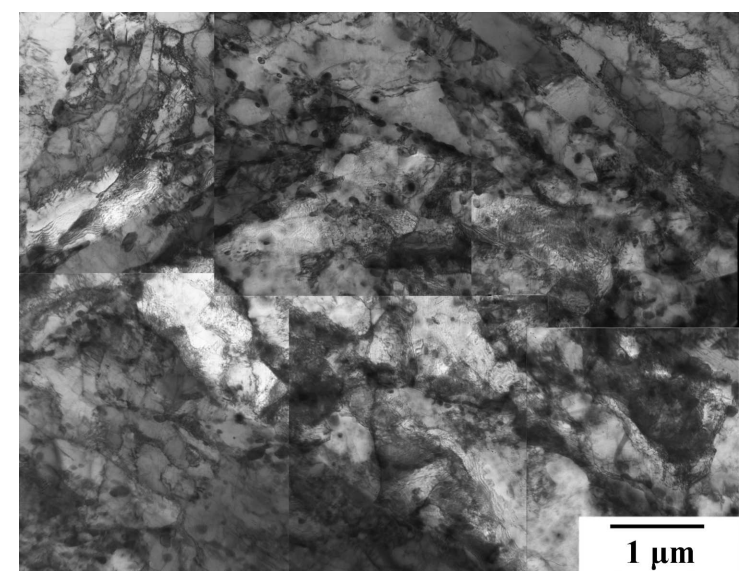

Fig. 1. TEM micrographs of the P92-type steel after normalization and tempering at $780{ }^{\circ} \mathrm{C}$.

Chemical composition of secondary phase particles after tempering (wt\%).

TABLE II

\begin{tabular}{l|c|c|c|c|c}
\hline \hline \multicolumn{1}{c|}{ Phases } & Cr & Fe & Mo & V & Nb \\
\hline $\mathrm{M}_{23} \mathrm{C}_{6}$ & 61.26 & 32.97 & 4.37 & 1.41 & - \\
V-rich MX & 15.16 & 3.94 & - & 66.17 & 14.79 \\
Nb-rich MX & - & 2.21 & - & 5.08 & 92.71
\end{tabular}

Increasing tempering temperature from 720 [8] to $780^{\circ} \mathrm{C}$ has no effect on the average size of prior austenite grains (PAGs). Part of tempered martensite lath structure (TMLS) transformed to subgrains that led to twofold decrease in lattice dislocation density [8]. The boundaries of PAGs and subgrains were decorated by nanoscale $\mathrm{M}_{23} \mathrm{C}_{6}$ carbides. No effect of tempering temperature on shape and dimensions of $\mathrm{M}_{23} \mathrm{C}_{6}$ carbides was found. In contrast, twofold increase in average of MX carbonitrides occurred with increasing tempering temperature from 720 to $780^{\circ} \mathrm{C}$ [8]. Two-phase separation of MX carbonitrides on V-rich and Nb-rich particles was observed (Tables I and II). However, the mean size and shape of $\mathrm{V}$ - and Nb-rich MX carbonitrides were nearly the same that is not typical for tempering at $\leq 750^{\circ} \mathrm{C}[1,10]$. No nanoscale V-rich MX carbonitrides with wing-like shape $[1,8]$ were found.

\subsection{Creep properties}

Creep strain vs. time and creep rate vs. time/strain curves at $650{ }^{\circ} \mathrm{C}$ and the nominal stress of $80 \mathrm{MPa}$ are shown in Fig. 2. These curves are typical for $9 \% \mathrm{Cr}$ martensitic steels containing secondary phase particles $[1,4-7]$.

At the applied stress of $80 \mathrm{MPa}$, the extended transient stage was observed; creep rate slowed down to the minimum value with increasing strain. Poor-defined steadystate flow could be distinguished. Minimum creep rate of $\approx 10^{-9} \mathrm{~s}^{-1}$ was approached in the strain interval 1$1.5 \%$ for $\approx 3000 \mathrm{~h}$. Rupture time was $9273 \mathrm{~h}$. Note that tertiary creep stage had one well-defined stage zone in contrast with 3\%Co-containing P92-type steel [5, 11].
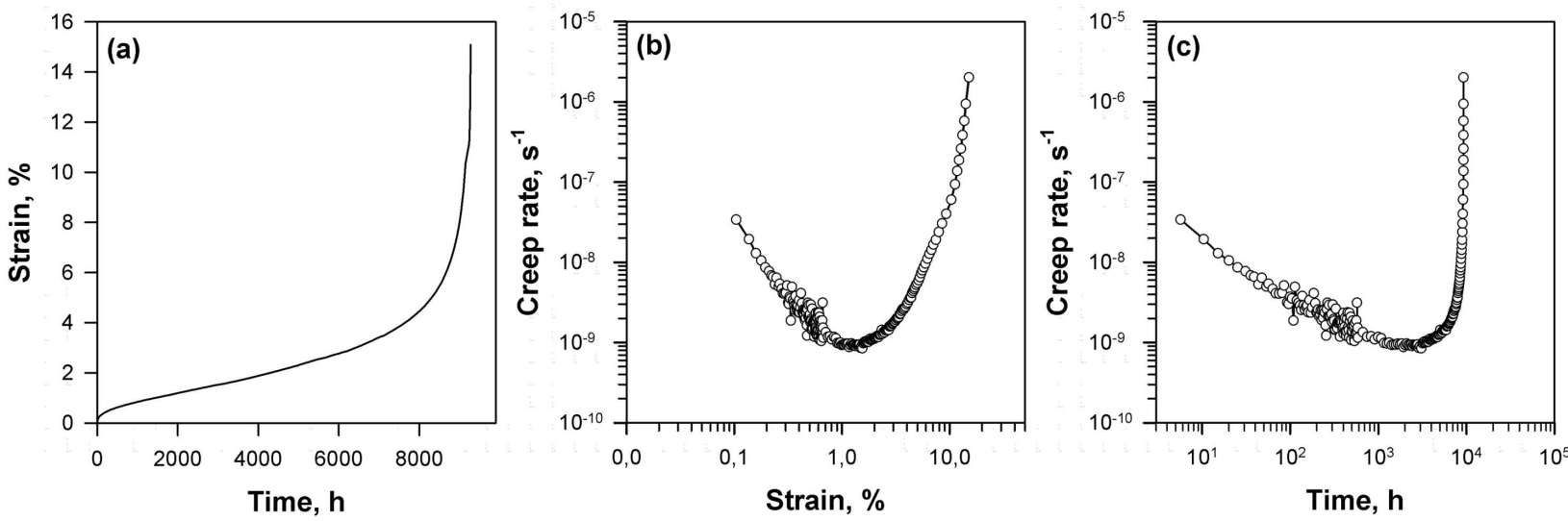

Fig. 2. Creep curves of steel studied upon creep at $650^{\circ} \mathrm{C}, 80 \mathrm{MPa}$.

\subsection{Microstructures after long-term aging and creep}

Crept microstructures of the steels are shown in Fig. 3, and structural parameters are summarized in Table III.

Effect of long-term aging on microstructure and a dispersion of secondary phase particles was examined in the grip portion of samples. No effect of long-term aging on PAGs and a dispersion of MX carbonitrides was found.

In the same time, transformation of TMLS into subgrain structure occurred (Fig. 3c) that led to the insignificant decrease in lattice dislocation density. It is worth noting that no evidence for recovery and subgrain for- mation during long-term aging at $600{ }^{\circ} \mathrm{C}$ for $\approx 7000 \mathrm{~h}$ and $650^{\circ} \mathrm{C}$ for $\approx 1200 \mathrm{~h}[8,12]$ was found. The average size of subgrains after tempering and after long-term aging was nearly the same (Table III). The Laves phase particles precipitated at PAG and subgrain boundaries like $\mathrm{M}_{23} \mathrm{C}_{6}$ carbides under long-term aging and creep. Extensive coarsening of $\mathrm{M}_{23} \mathrm{C}_{6}$ carbides and the Laves phase up to 280 and $650 \mathrm{~nm}$ was found under long-term aging. Dimensions of these boundary phases were significantly higher than those after long-term aging at $650^{\circ} \mathrm{C}$ for $\approx 1200 \mathrm{~h} \mathrm{[8].}$ 
Structural parameters of P92 steel after creep at $650{ }^{\circ} \mathrm{C}$ under the applied stress of $80 \mathrm{MPa}$.

TABLE III

\begin{tabular}{l|c|c|c|c|c|c|c|c}
\hline \hline \multirow{2}{*}{ Section } & \multirow{2}{*}{$\begin{array}{c}\text { Reduction } \\
\text { in area [\%] }\end{array}$} & \multirow{2}{*}{$D_{\text {PAG }}[\mu \mathrm{m}]$} & \multirow{2}{*}{$D_{\text {subgr }}[\mu \mathrm{m}]$} & \multirow{2}{*}{$\rho_{\perp} \times 10^{14}\left[\mathrm{~m}^{-2}\right]$} & \multicolumn{4}{|c}{$D_{\text {particles }}[\mathrm{nm}]$} \\
\cline { 5 - 8 } & 46 & $20 \pm 2$ & $1.30 \pm 0.3$ & $0.4 \pm 0.1$ & $300 \pm 30$ & $650 \pm 20$ & $90 \pm 8$ & $60 \pm 5$ \\
\hline neck & 8.5 & $20 \pm 2$ & $0.6 \pm 0.1$ & $1.0 \pm 0.5$ & $290 \pm 28$ & $550 \pm 20$ & $80 \pm 7$ & $60 \pm 5$ \\
gauge & - & $20 \pm 2$ & $0.40 \pm 0.1$ & $1.9 \pm 1.0$ & $280 \pm 28$ & $650 \pm 10$ & $55 \pm 5$ & $55 \pm 5$ \\
grip & & & &
\end{tabular}

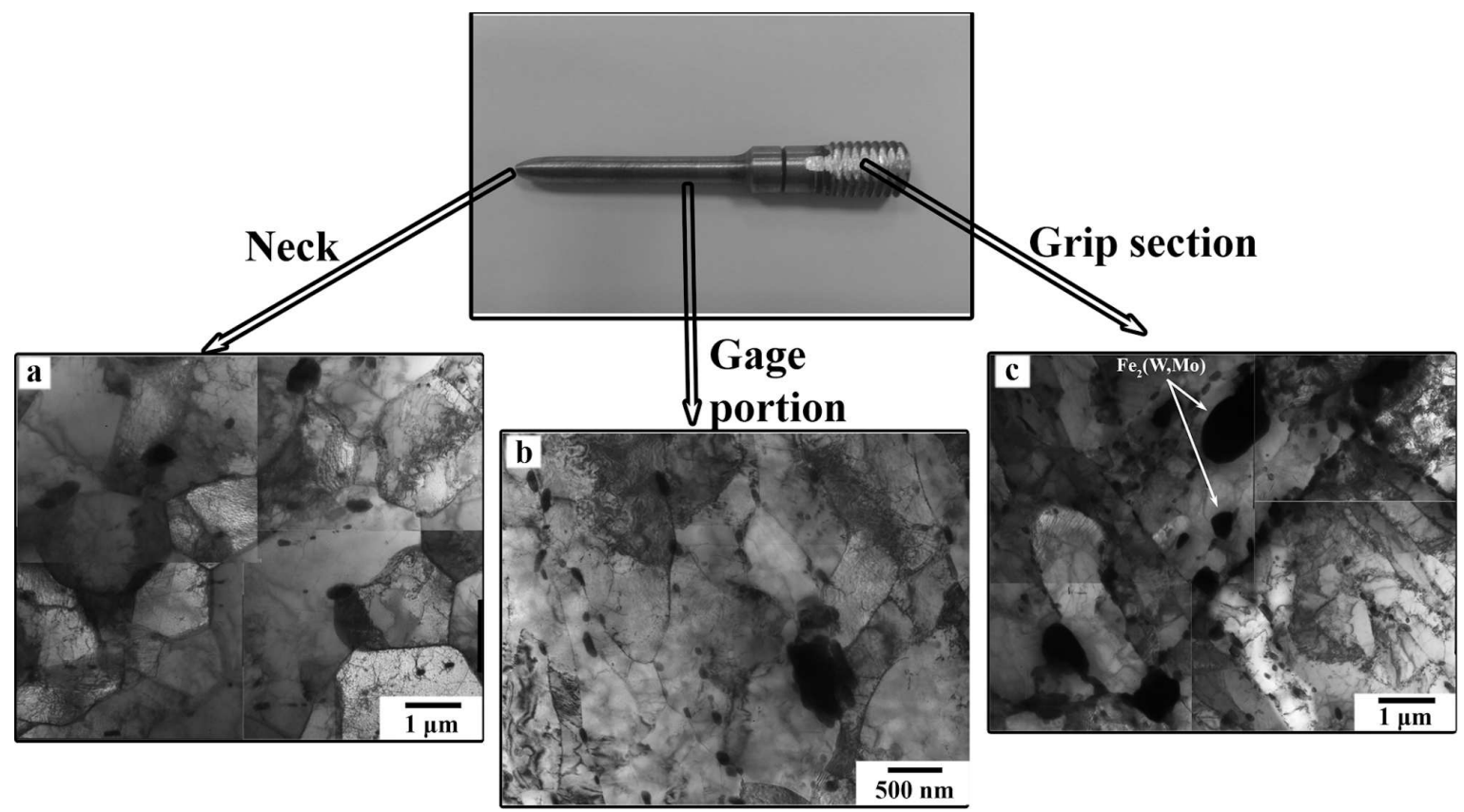

Fig. 3. Microstructures of steels studied from different sections of sample: (a) in the neck and (b) in the gauge portion $\left(650^{\circ} \mathrm{C}, 80 \mathrm{MPa}\right),(\mathrm{c})$ in the grip section $\left(650^{\circ} \mathrm{C}, 9273 \mathrm{~h}\right)$.

Creep promoted subgrain growth and a decrease in dislocation density. Well-defined subgrain structure evolved in the necked portion. No strain-induced growth of $\mathrm{M}_{23} \mathrm{C}_{6}$ carbides and the Laves phase was found. $\mathrm{M}_{23} \mathrm{C}_{6}$ carbides contained $\approx 70 \mathrm{wt} \% \mathrm{Cr}, 20-25 \% \mathrm{Fe}, \approx 5 \%$ $(\mathrm{Mo}+\mathrm{W})$ and $\approx 3 \% \mathrm{~V}$. The Laves phase particles contained $40-45 \mathrm{wt} \%(\mathrm{~W}+\mathrm{Mo})$ and $55-60 \%(\mathrm{Fe}+\mathrm{Cr})$. The $\mathrm{W} /$ Mo ratio in the Laves phase particles was 2-2.6. Particles of the Laves phase exhibited irregular shape and their size of $\approx 550-650 \mathrm{~nm}$ was nearly the same in all sections (Table III). V-rich MX particles were enriched by $\mathrm{Nb}$ and $\mathrm{Cr}$; and Nb-rich MX particles contained traces of $\mathrm{V}, \mathrm{Cr}$ and Fe after long-term aging and creep. No coarsening of Nb-rich particles with a round shape took place during long-term aging and creep, while there were few separate coarse $\mathrm{Nb}$-rich particles with a size of $\approx 200 \mathrm{~nm}$ in all sections of specimen. Strong strain-induced coarsening of V-rich MX carbonitrides occurred in the gauge and neck sections. The size of $\mathrm{V}$-rich particles increased from $55 \mathrm{~nm}$ to $\approx 80-90 \mathrm{~nm}$ after creep test (Table III).

\section{Discussion}

Subgrain coarsening is attributed to the balance between the pinning and the driving pressure for grain/subgrain growth. Two driving forces may induce subgrain coarsening. One of them is driving force originated from stored free lattice dislocations, and second one is driving force attributed to subboundary energy $[9,12]$. No difference in dislocation density in neighbor subgrains leads to negligible driving force due to stored dislocations. Driving force originated from lowangle boundary (LAB) energy can be evaluated as [9]:

$$
P_{\mathrm{LAB}}=\frac{2 \gamma}{r}=\frac{2 \gamma}{\alpha D},
$$

where $r$ is radius of curvature of subgrains $[\mu \mathrm{m}]$, which is proportional to grain/subgrain size $D, \alpha$ is constant.

The retarding force (the Zener drag) exerted by the particles, which are randomly distributed in ferritic matrix, depends on the size $d[\mathrm{~nm}]$ and the volume fraction $F_{v}[-]$ of particles as [5, 8-10, 13]:

$$
P_{z}=3 \gamma \frac{F_{v}}{d},
$$

where $\gamma$ is surface energy per unit area of the subgrain boundary $\left[\mathrm{J} \mathrm{m}^{-2}\right]$. Thus, particles exerting the retarding force must prevent the growth of subgrain structure.

An equilibrium subgrain size which may be achieved during polygonization can be estimated on the assumption of the driving and retarding forces are in a balance as follows: 


$$
D=\frac{2 \gamma}{\alpha P_{z}},
$$

where $\alpha=4[13]$. The total retarding force that depends on the volume fraction and the mean size of particles affects the value of equilibrium subgrain size. The calculated values of subgrain size in the steel studied in comparison with the experimental values are presented in Table IV. It is seen that experimental subgrain size in P92-type steel is significantly lower than their equilibrium value, estimated by Eq. (3). No retarding force exerted by coarsened of $\mathrm{M}_{23} \mathrm{C}_{6}$ carbides and the Laves phase particles occurs if their sizes are more than $300 \mathrm{~nm}$ and $500 \mathrm{~nm}$, respectively, after both long-term aging and creep. During long-term aging the subgrain growth is not controlled by coarsening of $\mathrm{M}_{23} \mathrm{C}_{6}$ carbides, the Laves phase particles and MX carbonitrides. In the grip portion, the static polygonization is not complete, because only the subgrain formation takes place, and no evidence for subgrain growth was revealed.

Calculated and experimental subgrain size.

TABLE IV

\begin{tabular}{c|c|c|c|c}
\hline \hline Section & $D_{\text {exper }}[\mu \mathrm{m}]$ & $\begin{array}{c}D_{\mathrm{P} 2=\mathrm{z}}[\mu \mathrm{m}] \\
\text { by Eq. }(3)\end{array}$ & $\begin{array}{c}D_{\infty}[\mu \mathrm{m}] \\
\text { by Eq. }(4)\end{array}$ & $\begin{array}{c}D_{\text {modif }}[\mu \mathrm{m}] \\
\text { by Eq. }(5)\end{array}$ \\
\hline neck & $1.30 \pm 0.40$ & 1.54 & 1.28 & 1.25 \\
gauge & $0.60 \pm 0.25$ & 1.48 & 1.72 & 0.84 \\
grip & $0.40 \pm 0.10$ & 1.27 & - & -
\end{tabular}

On the other hand, the subgrain size depends on the applied stress and creep strain under creep condition and can be estimated as (4):

$$
D_{\infty}=10 \frac{G b}{\sigma(1+\varepsilon)},
$$

where $G$ is a shear modulus [MPa], $b$ is the Burgers vector $[\mathrm{m}], \sigma$ is an applied stress [MPa], $\varepsilon$ is accumulated creep strain $[-]$.

Growth of subgrain size up to the strain-induced equilibrium value by Eq. (4) indicates the completeness of recovery and polygonization processes. In the gauge section, experimental subgrain size in the P92-type steel does not reach its equilibrium value, estimated by Eq. (4), whereas in the neck, the calculated and the experimental subgrain sizes are nearly the same.

The expression (4) can be modified [14] by addition of parameters of initial structure and can be estimated as (5):

$$
\log D_{\infty}=\log D_{\infty}+\log \left(\frac{D_{0}}{D_{\infty}}\right) \exp \left(-\frac{\varepsilon}{k(\sigma)}\right),
$$

where $D_{0}$ — initial subgrain size after tempering $[\mathrm{m}]$, equilibrium subgrain size from Eq. (4), $\varepsilon-$ accumulated creep strain, $k(\sigma)$ - growth constant, 0.12 [14].

The modification of Eq. (4) by the addition of initial structure parameters gives the calculated subgrain size close to experimental one in the gauge section and the neck (Table IV). The increase in accumulated creep strain provokes the fully polygonized equiaxed structure with a very large grain size.
Thus, during long-term creep the subgrain growth was determined by initial structural parameters, accumulated creep deformation and applied stress.

\section{Conclusions}

The microstructures of a P92-type steel tempered at $780^{\circ} \mathrm{C}$ and crept at $650{ }^{\circ} \mathrm{C}$ under an applied stress of $80 \mathrm{MPa}$ were studied. The main results can be summarized as follows.

1. Tempering at $780^{\circ} \mathrm{C}$ led to formation of subgrain structure instead of tempered martensite lath structure (TMLS) with a mean subgrain size of $0.4 \mu \mathrm{m} . \mathrm{M}_{23} \mathrm{C}_{6}$-type particles with an average size of $105 \mathrm{~nm}$ precipitated on interlath and high-angle boundaries. MX carbonitrides with a mean size of $55 \mathrm{~nm}$ precipitated homogeneously throughout the ferritic matrix.

2. The structural changes were related to a gradual growth of ferrite subgrains and replacement of TMLS by subgrain structure. Creep strain strongly promotes this process. The mean subgrain sizes were $0.4,0.6$, and $1.3 \mu \mathrm{m}$ in the grip section, the gauge portion and the neck, respectively.

3. During long-term creep the subgrain growth was determined by initial structural parameters, accumulated creep strain and applied stress but not by balance between driving and retarding forces.

\section{Acknowledgments}

The study was financially supported by the Russian Science Foundation, under grant No. 17-73-10380. The authors are grateful to the staff of the Joint Research Center, "Technology and Materials", Belgorod National Research University for their assistance with instrumental analysis.

\section{References}

[1] F. Abe, T.-U. Kern, R. Viswanathan, Creep Resistant Steels, Woodhead Publishing in Materials, Cambridge 2008, p. 678.

[2] T.-U. Kern, M. Staubli, B. Scarlin, ISIJ Int. 42, 1515 (2002).

[3] R.O. Kaybyshev, V.N. Skorobogatykh, I.A. Shchenkova, Phys. Met. Metall. 109, 186 (2010).

[4] A. Kipelova, M. Odnobokova, A. Belyakov, R. Kaibyshev, Metall. Mater. Trans. A 44A, 577 (2013).

[5] N. Dudova, A. Plotnikova, D. Molodov, A. Belyakov, R. Kaibyshev, Mater. Sci. Eng. A 534, 632 (2012).

[6] F. Abe, Mater. Sci. Eng. A 510-511, 64 (2009).

[7] A. Kostka, K.-G. Tak, R.J. Hellmig, Y. Estrin, G. Eggeler, Acta Mater. 55, 539 (2007). 
[8] V. Dudko, A. Belyakov, D. Molodov, R. Kaibyshev, Metall. Mater. Trans. A 44A, 162 (2013).

[9] F.J. Humphreys, M. Hatherly, Recrystallization, Related Annealing Phenomena, 2nd ed., Elsevier, Oxford 2004, p. 605.

[10] A. Fedoseeva, N. Dudova, R. Kaibyshev, Mater. Sci. Eng. A 654, 1 (2016).

[11] A. Fedoseeva, N. Dudova, R. Kaibyshev, Mater. Sci. Forum 879, 548 (2016).
[12] A. Fedoseeva, I. Nikitin, V. Dudko, N. Dudova, R. Kaibyshev, in: Proc. 8th Int. Conf.: Advances in Materials Technology for Fossil Power Plants, 2016, p. 479 .

[13] A. Kipelova, R. Kaibyshev, A. Belyakov, D. Molodov, Mater. Sci. Eng. A 528, 1280 (2011).

[14] W. Yan, W. Wang, Y. Shan, K. Yang, Frontiers Mater. Sci. 7, 1 (2013). 